\title{
Dynamic Adverse Selection and Debt*
}

\author{
Gilles Chemla \\ Universitat Pompeu Fabra \\ and \\ Antoine Faure-Grimaud \\ London School of Economics \\ First Draft: March 1996 \\ This draft: December 18, 1996
}

Keyword: dynamic adverse selection, durable good, ratchet effect, renegotiation, financial constraint, debt.

JEL classification: D42, D82, G32, L14.

\footnotetext{
*Universitat Pompeu Fabra and London School of Economics, respectively. This paper was written when Chemla was a lecturer at the London School of Economics. We would like to thank Patrick Bolton, Xavier Freixas, Denis Gromb, Jane Marrinan, Jean Tirole as well as seminar participants at the 1996 Econometric Society European Meeting, the LSE Financial Markets Group Lunchtime Seminar, Universitat Pompeu Fabra, Universiteit Leuven and GREMAQ-IDEI (Université de Toulouse) for helpful comments. Financial support from the Fondation du Crédit National and from the European Commission is gratefully acknowledged. All errors are ours.
} 


\section{Non-Technical Abstract:}

In many long-term relationships, privately informed parties may be reluctant to reveal their information in order to benefit from their informational advantage in the future. For instance, a worker may not want to reveal that his productivity is high in order to avoid higher performance requirements in the future. A buyer whose valuation is private information and who faces a durable good monopolist may be better off not buying the good early to induce the monopolist to lower the price in the future. This paper provides a solution to such problems which is consistent with casual observation. We point out that an uninformed party can induce another party to reveal its private information by choosing a high level of (renegotiable) debt. Our argument is based on the idea that debt is a credible commitment to end long term relationships. We show that the strategic advantage of debt increases with good durability and we briefly address the financing decision of a regulated firm.

\section{Technical Abstract:}

This paper argues that the strategic use of debt favours the revelation of information in dynamic adverse selection problems. Our argument is based on the idea that debt is a credible commitment to end long term relationships. Consequently, debt encourages a privately informed party to disclose its information at early stages of a relationship. We illustrate our point with the financing decision of a monopolist selling a good to a buyer whose valuation is private information. A high level of (renegotiable) debt, by increasing the scope for liquidation, may induce the high valuation buyer to buy early at a high price and thus increase the monopolist's expected payoff. By affecting the buyer's strategy, it may reduce the probability of excessive liquidation. We investigate the consequences of good durability and we examine the way debt may alleviate the ratchet effect. 


\section{Introduction}

In May 1989 Sealed Air Corporation (SAC) announced a one-time leveraged special dividend of $\$ 40$ per share, almost equal to the equity price. Before this announcement SAC had never paid a dividend exceeding 18 cents per share. To finance this special dividend, SAC borrowed $\$ 307$ million (using private and public debt) representing $136 \%$ of total assets. The poor rating of this debt reflected the risk associated with this operation. Interestingly, this leveraged special dividend was followed by a $29 \%$ increase in sales, a $20 \%$ decrease in inventories and a $64.5 \%$ increase in the operating profit by 1992 . The total value of the firm increased by $80 \%$ over the same years. There is no evidence whatsoever that these performances were due to exogenous factors ${ }^{1}$.

SAC manufactures protective packaging materials. Many of its products were protected from product market competition by patents and the firm entertained long-term relationships with most of its clients. It had been run by the same CEO since 1971 and enjoyed a profitable growth during these years. Before the special dividend, SAC was already a successful company.

Some of the spectacular increase in profits which followed the special leverage of 1989 could be attributed to a "free cash flow" reduction effect (Jensen (1986)). Wruck (1994) points out some evidence in that direction: managers felt that cash flows were abundant and that the firm did not know what to do with these cash flows. Nevertheless, although the abundance of cash flow is a necessary condition for this theory, it is not sufficient: debt increases performance only when managers divert these cash flows to their own benefit instead of paying them out to shareholders: "the problem (with free cash flow) is how to motivate managers to disgorge the cash rather than invest it at below the

\footnotetext{
${ }^{1}$ Our source for this information on SAC is Wruck's (1994) excellent paper. In particular, Wruck did not find any evidence of a takeover threat. She shows that tax shields can only explain a very small percentage of the profit increase. In addition, a signalling argument (Ross (1977)) is not consistent with the poor rating of debt and the absence of abnormal stock price reaction after the announcement of the leveraged special dividend.
} 
cost of capital or waste it through organizational efficiencies. [...] Such cash flow should be paid out to shareholders [...] However, payment of cash reduces the resources controlled by managers" (Jensen 1988). Debt is beneficial because it disciplines managers. Wruck (1994) clearly shows that the whole story of $\mathrm{SAC}$ is an example, maybe unusual, of no conflict between shareholders and managers: "the evidence for SAC is completely inconsistent with poor performance due to management entrenchment". And the very fact that managers decided to pay out to shareholders this excess of cash (the efficient decision), plus a huge income financed by debt, contradicts the existence of serious agency problems associated with management. Finally, the efficiency effects of a free cash flow reduction are deemed to be more important in a declining industry, which is not the case of SAC.

More generally, there may have been moral hazard issues at other levels of the organization. In the absence of proper monetary incentive schemes, debt may reduce these agency costs. However, there is no evidence of moral hazard problems at low organizational levels or commitment difficulties at higher levels of the hierarchy which are sufficiently important to explain the spectacular increases in efficiency and sales or the substantial decrease in inventories. An alternative argument, not based on any moral hazard issues, may better explain the beneficial role of debt. In the case of SAC, Wruck (1994) suggests that efficiency enhancement was due to a change of "culture". Debt was "a tool to disrupt the status quo". The aim of our paper is to provide an economic explanation of this behavioral modification.

Our argument is based on the existence of dynamic adverse selection problems in organizations. A well-known example is the ratchet effect: agents engaged in a long-term relationship are reluctant to reveal their private information at early stages. For example, a worker refuses to reveal a high productivity because he anticipates more challenging performance requirements and hence the loss of corresponding informational rents in the future. A buyer 
whose buying decision repeats over time is unwilling to pay a high price today because he expects that the seller will consequently charge high prices for all subsequent periods. In both cases, firm's profits are decreased by the fact that partners adopt long-term objectives. Debt is beneficial because it creates scope for liquidation which may end long-term relationships. The strategic use of debt favours information revelation, i.e. it helps to solve dynamic adverse selection problems.

This paper analyses this basic idea in a particular setting. We study the financing decision of a monopolist selling a good to a buyer with private information about his valuation. We show that when the relationship is a long-term one, that is when the monopolist charges the buyer on at least two different occasions, the strategic use of debt induces the buyer to reveal his information early. Crucial features of dynamic adverse selection problems are that the buyer's early decision reveals information about his type and that the monopolist (or principal) can use information strategically when deciding on her subsequent contract offers. Hence, it is costly for the buyer to reveal information and the monopolist's contract offers are subject to the constraint that the buyer's expected rents from not revealing information are lower than the utility from revealing it at an early stage. We point out that the strategic use of debt may relax this constraint: not revealing information may lead to cash constrained, and thus inefficient, debt renegotiation ending up in (partial) liquidation which reduces a buyer's expected rent of mimicking a lower valuation buyer. From this point of view, debt is a credible commitment with a third party. Using debt as a mechanism to elicit information enables the monopolist to charge a higher price and to increase her profit.

The analysis suggests a number of extensions. First, a crucial feature of our argument is that liquidation affects the quantity to be sold in the future. A priori, the monopolist can choose either to produce to order (or adopt just in time manufacturing) or to produce to market. If there is production to 
market, the quantity offered will be available after it is produced regardless of the liquidation decision. Thus, partial liquidation will only restrict the quantity offered at the next stage under production to order. Hence, the monopolist's payoff and debt are higher under production to order than under production to market ${ }^{2}$.

Second, a dynamic adverse selection problem decreases the monopolist's profit all the more as the good is more durable. Hence, the benefit of the strategic use of debt to the monopolist increases with the durability of the good. The more durable the good, the higher the possible increase in price in the first stage and the lower the profit to be made in the second stage. This suggests that ceteris paribus debt should increase with the durability of the $\operatorname{good}^{3}$. This idea that debt may increase the expected profit of a monopolist selling a durable good is to be contrasted with Titman (1984). Titman argues that when the buyers' valuation depends on after-sale services, debt decreases the value of durable goods: the higher the debt level, the higher the probability of bankruptcy and the lower the ability to grant after-sale services. Although the point is relevant, Titman ignores the durable good monopolist pricing problem which turns out to depend on the financial decisions. Here, we abstract from after-sale services and focus on this interaction between debt and pricing strategy. Debt induces the buyer to purchase earlier at a higher price and allows the monopolist to appropriate a higher share of the surplus.

The role of debt as a hard claim to provide incentives in moral hazard situations has often been emphasized. In the absence of commitment problems, these incentives could generally be provided by monetary schemes. The literature on the role of debt in commitment problems has mostly considered static moral hazard issues (Jensen and Meckling (1976), Grossman and Hart (1982),

\footnotetext{
${ }^{2}$ This point that the strategic use of debt works better with a production to order matches SAC's decrease in inventories after 1989.

${ }^{3}$ It also implies that we may expect our effect to be particularly relevant in situations characterised by repeated transactions amongst agents: the more important the long-term relationships, the more drastic the "cultural" change associated with leverage should be.
} 
Jensen (1986), Hart (1993), Perotti and Spier (1993)). Harris and Raviv (1990) exhibit a positive effect of debt due to its informational role. Namely, debt repayments reveal information which is used to discipline management. In our paper, debt is only accompanied by a possibility of terminating the relationship, which is sufficient to induce the privately informed party to truthfully reveal its information.

Section 2 describes the strategic use of an optimal debt contract in Coasian dynamics. It provides a number of extensions and applications such as the effects of money diversion and cost padding, the timing of production and good durability. In section 3 , we address the ratchet effect, allowing for variable quantities and non linear pricing rules. We also briefly discuss how the buyer's capital structure affects the monopolist's pricing strategy. Section 4 concludes.

\section{Coasian Dynamics and the Optimal Debt Contract}

The two basic dynamic adverse selection problems are the Coasian dynamics faced by a durable good monopolist and the ratchet effect in long-term relationships. In this section, we first address the financing decision of a durable good monopolist.

Coase (1972) first observed that the pricing problem of such a monopolist is constrained by the buyer's expectation that the price will decrease over time. The Coasian intuition is that the durable good monopolist competes with herself over time. When the monopolist charges different consecutive prices, following the rejection of a price, she updates her beliefs about the buyer's valuation and decreases her price over time. Anticipating this, the buyer with a high valuation may be better off waiting for a decrease in the price before buying.

We point out that a buyer with a high valuation may choose to buy early when the monopolist may be (partly) liquidated before the price decreases. 
Hence, the monopolist may wish to choose a high level of debt to commit to this ex post inefficient behaviour. We then give a number of comparative statics results.

We focus on debt renegotiation and describe an "ideal" property of an optimal debt contract. Debt forces a high valuation buyer to pay the static monopoly price at the beginning of the game. In addition, there is no scope for inefficient liquidation after the sale takes place. The debt level is chosen to ensure that no sale triggers default. This leads to cash constrained (and thus inefficient) debt renegotiation and total liquidation of the firm.

\subsection{The Model}

The model combines simplified versions of Hart and Tirole (1988) for the product market and of Hart and Moore (1989) and Hart (1995) for the financial contract.

\subsubsection{The product market}

A monopolist $M$ has the capacity to produce $q \in\{0,1\}$ units of a durable good to be sold in stage 1 or 2 to a single buyer. The production cost is zero. A durable good is defined such that when the sale takes place in stage 1, the buyer consumes the good in both stages 1 and 2 .

The buyer has private information about his valuation $v \in\left\{V_{l}, V_{h}\right\}$, with $V_{h}>V_{l}$. Initially, it is common knowledge that $v=V_{h}$ with probability $\lambda_{1}$. We make the usual assumption that, in a static framework without financial constraints, the monopolist would prefer selling the good at $p_{1}=V_{h}$ with probability $\lambda_{1}$ to selling it for sure at price $p_{1}=V_{l}$, i.e. $\lambda_{1}>\bar{\lambda} \equiv V_{l} / V_{h}$.

\subsubsection{The financial contract}

The monopolist has an initial wealth of $w$ and needs capital $K>w$ to buy an asset necessary to enter the product market. $K$ only needs to be paid once at the beginning of the relationship. The firm can be liquidated (and the 
asset sold), generating a return $L_{t}$ at the end of stage $t$ whether the good was produced and sold or not. The asset depreciates $\left(L_{1}<K\right)$ and we assume $L_{2}=0^{4}$. The liquidation decision can be made either by the monopolist or by the creditor. Entering the product market is profitable. We assume $L_{1}<\delta V_{l}$, where $\delta$ is the discount factor common to all agents. That is, liquidating the asset at the end of stage 1 is inefficient if the good is not sold.

Following Hart and Moore (1989, 1996) and Bolton and Scharfstein (1996), we assume that the monopolist can divert cash flows more easily than physical assets. Formally, returns from liquidation are verifiable while profits from the sale of the good are not (they can be used for perks). In other words, the monopolist cannot be convicted of stealing the operational profit. One reason for this is that there is a probability that this profit is null.

We now turn to the set of financial contracts. Before borrowing, the monopolist can invest some of her wealth $w_{0} \leq w$ in a two period project with a zero rate of non verifiable return. For instance, the money can be secretly invested in a tax heaven. To bring it back would disclose tax evasion and lead the monopolist to jail or to pay a heavy penalty. Let $w_{p}=w-w_{0}$ be the publicly known wealth of the monopolist which is invested in the project described in the previous subsection. The monopolist borrows an amount $B \geq K-w_{p}$ from a creditor against the pledge to repay $R_{1}$ and $R_{2}$ at the end of stages 1 and 2 whenever possible. As profits are non-verifiable, feasible contracts can only specify that the firm repays the promised amount or the creditor has the right to liquidate the asset.

Nevertheless, before liquidation takes place, the stream of promised repayments can be renegotiated. This is a central feature of our model: introducing a commitment possibility with a third party would allow the monopolist to commit to a price and, of course, would solve the coasian dynamics. However, such an agreement is not renegotiation-proof because the monopolist could

\footnotetext{
${ }^{4}$ in a past version, we investigated the effect of asset durability and qualitative results were unchanged.
} 
always bribe the third party ex post to lower the price.

At the final stage, the creditor can obtain nothing from the operational profit as the monopolist will always divert it. However, at the first stage, the monopolist may be prepared to give up some of the operational profit to the creditor to avoid liquidation. For simplicity, we also assume that the monopolist has all bargaining power in case of renegotiation in stage 1 and that the creditor cannot seize the monopolist's savings (that is, in stage 1 , $\left.B-\left(K-w_{p}\right)\right)$.

Without loss of generality, we assume that the market for creditors is perfectly competitive. All parties are risk-neutral.

\subsubsection{Definition of the equilibrium}

The sequence of events is as follows:

- In stage 1 , the monopolist chooses $w_{p}$ and $w_{0}$ and borrows an amount $B$ from the creditor against the pledge to repay $\left\{R_{t}\right\}$. $M$ charges a price $p_{1}$. The buyer decides whether to buy or not. Accordingly, $M$ produces and sells the quantity ordered. Renegotiation may take place and $M$ satisfies her financial obligations.

- In stage 2 , if the monopolist carries on, she chooses a price $p_{2}$. The buyer chooses whether to buy or not. $M$ sells the asset and repays the creditor.

In case of default, renegotiation implies that a fraction $1-f$ of the asset is liquidated. The production capacity at stage 2 is then $f$. Alternatively, $1-f$ may be thought of as the probability of liquidation following a default. For a given financial contract, a Perfect Bayesian Equilibrium in the product market is defined by:

i) a sequence of prices $\left\{p_{1}, p_{2}\right\}$ characterizing the monopolist's strategy, conditional upon her beliefs regarding the buyer's type (an offer at date 2 
occurs only if the prior offer was rejected). According to the renegotiation outcome, $M$ can supply either a quantity $f$ or 0 at price $p_{2}$.

ii) a sequence of buyer's decisions whether to buy or not the good supplied. Let $x_{t}^{i}\left(p_{t}\right)$ be the probability to buy at price $p_{t}(t=1,2)$.

iii) a probability distribution defining the monopolist's beliefs derived from equilibrium strategies using Bayes' rule whenever possible.

Our equilibrium definition does not involve the creditor's strategy. This is because, from the creditor's perspective, the market equilibrium is irrelevant since returns are non-verifiable: his strategy depends only on the liquidation values.

\subsection{Coasian Dynamics and Financial Constraints}

We proceed by backward induction. The strategy of a buyer of type $i$ in stage 2 is:

$$
x_{2}^{i}\left(p_{2}\right)= \begin{cases}1 & \text { if } p_{2} \leq v_{i} \\ 0 & \text { otherwise }\end{cases}
$$

Let $\lambda_{2}\left(p_{1}\right)$ be the probability that $i=h$ knowing that $p_{1}$ was rejected. The monopolist plays:

$$
p_{2}= \begin{cases}V_{h} & \text { if } \lambda_{2} V_{h}>V_{l} \\ V_{l} & \text { otherwise }\end{cases}
$$

Since the monopolist has all bargaining power with the creditor in the renegotiation game at the end of stage 1 , the creditor cannot be repaid more than $L_{1}$. The creditor refuses to lend more than $L_{1}$. Thus, $w_{p}$ must satisfy $w_{p} \geq K-L_{1}$. Indeed, the creditor will get $D_{1}=\min \left\{R_{1}, L_{1}\right\}$ and $D_{2}=0$. Given that the market for creditors is perfectly competitive, $D_{1}=B$.

Two cases arise:

- if the buyer bought in stage $1, M$ closes the firm and sells the assets. 
The creditor is repaid $D_{1}{ }^{5}$.

- if the buyer did not buy in stage 1 , then the continuation value is at least $\delta V_{l}>L_{1}$. When the creditor liquidates a fraction $1-f$ of the assets in stage 1 , the monopolist loses at least $(1-f)\left(\delta V_{l}-L_{1}\right)$. Thus, the monopolist will prefer to pay back in cash first and liquidate as little as possible. Once the monopolist received $B$ and invested $K$, the amount of cash left $B-\left(K-w_{p}\right)$ is not high enough to repay $D_{1}\left(\right.$ as $\left.D_{1}=B\right)$. Since liquidation is inefficient, the monopolist will repay as much as possible in cash. Nonetheless, she will have to accept the liquidation of a fraction $1-f$ of the assets such that $B-\left(K-w_{p}\right)+(1-f) L_{1}=D_{1}$ :

$$
f=1-\frac{K-w_{p}}{L_{1}}
$$

Note that forgiving some of the debt today or contracting a new loan to partly repay the debt against a reimbursement at $t=2$ is impossible: as $L_{2}=0, D_{2}$ is null ${ }^{6}$.

In stage 1, buyers' strategies can be characterized as follows. The buyer of type $l$ cannot expect any surplus if he waits. His strategy in stage 1 is:

$$
x_{1}^{l}\left(p_{1}, R_{1}\right)=\left\{\begin{array}{l}
1 \quad \text { if } p_{1} \leq V_{l}(1+\delta) \\
0 \quad \text { otherwise }
\end{array}\right.
$$

Indeed, if $p_{1}=V_{l}(1+\delta)$, then the buyer accepts with probability 1 whatever his type. Consider now $p_{1}>V_{l}(1+\delta)$. A type $h$ buyer is willing to buy at $t=1$ if and only if he gets at least what he would obtain by deferring his purchase. If he expects a fraction $1-f$ of the asset to be liquidated in case he does not buy, then he buys with probability 1 for $\left\{p_{1}, p_{2}\right\}$ satisfying

\footnotetext{
${ }^{5}$ The proceeds of a liquidation triggered by the monopolist are verifiable.

${ }^{6}$ One may think that following a liquidation $M$ could decide to buy a new asset to replace the initial investment of $K$. The cost of such a policy is $K$. It seems natural to assume that the depreciation process is identical to the one which occurred during the first period. Hence, the liquidation value of an asset bought at the beginning of the second period is also $L_{1}$ at the end of $t=2$. But the difference is that now $M$ has no more cash $w_{p}$ to invest in the project. As $K>L_{1}$ such a solution is not feasible.
} 
$V_{h}(1+\delta)-p_{1} \geq \delta f\left(V_{h}-p_{2}\right)$. For such prices, a buyer of type $h$ buys with probability 1 and a buyer of type $l$ does not buy. The ex post beliefs of the monopolist are $\lambda_{2}=0$, i.e. the equilibrium is fully separating. Hence, $p_{2}=V_{l}$ and the maximum fully separating stage 1 price is:

$$
\hat{p}_{1}=V_{h}(1+\delta)-\delta f\left(V_{h}-V_{l}\right)
$$

Let us now consider the case where the monopolist charges $p_{1}>\hat{p}_{1}$. In this range, only semi-separating equilibria (where type $h$ randomizes) may exist. This type of equilibrium requires the monopolist be indifferent between $p_{2}=V_{l}$ and $p_{2}=V_{h}{ }^{7}$. Therefore, the probability $x$ that a high valuation buyer buys at $t=1$ must be such that $\lambda_{2} V_{h}=V_{l}$, i.e.:

$$
\lambda_{2}=\frac{\lambda_{1}(1-x)}{\lambda_{1}(1-x)+\left(1-\lambda_{1}\right)}=\frac{V_{l}}{V_{h}}=\bar{\lambda}
$$

In equilibrium, the buyer of type $h$ must be indifferent between accepting and rejecting a first stage offer. Let $\sigma_{2}=\operatorname{Prob}\left\{p_{2}=V_{l}\right\}$. This requires $V_{h}(1+\delta)-p_{1}=\delta \sigma_{2} f\left(V_{h}-V_{l}\right)$. If the buyer did not buy, the monopolist's expected payoff at stage 2 is $\delta\left[\sigma_{2} V_{l}+\left(1-\sigma_{2}\right) \bar{\lambda} V_{h}\right]=\delta V_{l}$. As the second stage payoff does not depend on the price strategy, the monopolist charges the highest possible price at $t=1$, i.e. $p_{1}=V_{h}(1+\delta)$.

Therefore, the separating and semi-separating expected utilities of the monopolist are:

$$
\begin{gathered}
U_{s} \equiv \delta f_{s} V_{l}+\lambda_{1}\left[V_{h}\left(1+\delta\left(1-f_{s}\right)\right)+L_{1}-\left(K-w_{p, s}\right)\right]+w_{0, s} \\
U_{s s} \equiv \frac{\lambda_{1}-\bar{\lambda}}{1-\bar{\lambda}}\left[V_{h}(1+\delta)-\left(K-w_{p, s s}\right)+L_{1}\right] \\
+\frac{1-\lambda_{1}}{1-\bar{\lambda}} \delta f_{s s} V_{l}+w_{0, s s}
\end{gathered}
$$

\footnotetext{
${ }^{7}$ If $p_{2}=V_{h}$ with probability 1 , a buyer strictly prefers buying at $t=1$. If $p_{2}=V_{l}$ with probability 1 , either the equilibrium is fully separating $\left(p_{1} \leq \hat{p}_{1}\right)$ or the buyer is strictly better off waiting for the decrease in price.
} 
where subscripts $s$ and $s s$ hold for separating and semi-separating, respectively ${ }^{8}$. For a given financial contract, the monopolist's equilibrium strategy is to choose $p_{1}$ leading to either the separating or the semi-separating outcome according to the values of $\lambda_{1}$. In turn, the financial contract chosen by the monopolist depends on the anticipated equilibrium in the product market.

$U_{s}$ increases with the liquidated fraction which itself decreases with the wealth invested in the project. A higher liquidated fraction increases the buyer's willingness to buy at stage 1 . The monopolist can then charge a higher price to a high valuation buyer. This expected benefit is higher than the expected cost of liquidation -equal to the profit lost at $t=2$ if the buyer is a low valuation one- for $\lambda_{1} \geq \bar{\lambda}$. Therefore, the monopolist wants to deposit as much money as possible in the alternative project. Nevertheless, she has to invest a minimum amount $w_{p, s}=K-L_{1}$ to obtain the funding necessary to enter the product market. In a separating equilibrium, the monopolist makes sure that no sale triggers complete liquidation (the equilibrium value $f_{s}$ equals zero). The expectation of liquidation induces the buyer to buy, which makes complete liquidation optimal ex post ${ }^{9}$.

The monopolist's preferences are different in the semi-separating equilibrium. Whatever the financial contract, the stage 1 price is equal to $V_{h}(1+\delta)$. Any increase in the liquidated fraction has no positive effect on stage 1 profits. In constrast, the possibility of liquidation decreases the stage 2 payoff. Thus, the semi-separating utility is increasing in $f$ and the monopolist wants to avoid the scope for liquidation. To this purpose, she invests all her wealth in the durable good project. We thus obtain:

Proposition 1 : For all $\lambda_{1}$, the monopolist invests $w_{p}=K-L_{1}$ in the durable good project and borrows $B=L_{1}=K-w_{p}$ (borrowing capacity). Hence, default

\footnotetext{
${ }^{8}$ Following the literature, the parameter values make sure that the (uninteresting) pooling equilibrium is dominated.

${ }^{9}$ This point is similar to Fudenberg et al (1987) where a fixed cost of continuation corresponds here to a decrease in the liquidation value.
} 
triggers her complete liquidation. The only equilibrium in the product market is a fully separating one with a stage 1 price $p_{1}=V_{h}(1+\delta)$.

\section{Proof: See Appendix.}

The monopolist chooses the fraction to be liquidated in case of default so as to obtain a fully separating equilibrium in the product market. Investing the minimum amount of wealth in the project ensures that a potential semiseparating equilibrium in traditional Coasian dynamics is replaced by a unique fully separating equilibrium. With $w_{0}=w-\left(K-L_{1}\right)$, the monopolist is committed to be completely liquidated if the high valuation buyer does not buy. This forces the high valuation buyer to purchase with probability 1 for prices up to his valuation in stage 1 . This credible commitment arises from the financial constraint. Even renegotiable, debt restores full static monopoly power ${ }^{10}$.

Note that if the equilibrium were semi-separating without money diversion, then some inefficient liquidation would occur with probability $\left(1-\lambda_{1}\right) /(1-\bar{\lambda})$. Being financially constrained allows the monopolist to switch to a separating equilibrium which implies that inefficient liquidation only occurs with probability $1-\lambda_{1}$. Thus, a harder financial constraint and a higher level of debt may decrease the probability of inefficient liquidation.

In addition, in the traditional Coasian dynamics without debt, the low valuation buyer purchases the good when the price goes down. In contrast, the strategic use of debt makes sure that the good is produced and sold to the high valuation buyer only, i.e. with probability $\lambda_{1}$ only. The price is always too high for the low valuation buyer to buy the good. Hence, the strategic use of debt

\footnotetext{
${ }^{10} \mathrm{~A}$ Bolton-Scharfstein debt contract would also capture our point. In Bolton and Scharfstein (1996), there is no temporal correlation between the payoffs to the monopolist. In their setup, this implies that the optimal financial contract is less "tough" than a standard debt contract. In a product market characterized by dynamic adverse selection, the monopolist competes with herself over time. This implies that the optimal Bolton-Scharfstein financial contract is a standard debt contract where there is liquidation with probability 1 (resp. 0) if low (resp. high) profits are reported by the monopolist.
} 
decreases social surplus. This is natural since debt enables the monopolist to restore her static monopoly power.

A direct interpretation of this proposition is insufficient to fully explain the increase in SAC's profit, the example mentioned in the introduction. According to Wruck, the increase in profit was also due to improvements of the internal efficiency, while this proposition emphasizes the debt capacity to promote external efficiency. Moreover, protective packaging systems are not durable goods. The next section shows that our effect pertains even if goods are non durable as long as the valuation of the buyer is private information. It also provides a motivation for the usefulness of debt to solve for internal dynamic adverse selection problems. Nonetheless, it must already be noted that a substantial part of the increase in sales which followed the special dividend can be attributed to the type of effect characterized in Proposition 1. The existence of patents protected SAC from competition in many markets. The possibility of bankruptcy may have influenced the behavior of large industrial clients in these markets in a way similar to the one described above.

\subsection{Extensions and Applications}

\subsubsection{Cost Padding and Money Diversion}

We have seen that the binding financial constraint, $L_{1}=K-w_{p}$, can be obtained by investing in another two period project. Alternatively, the monopolist could make sure that the liquidation value $L_{1}$ is low enough, i.e. that the asset depreciates fast enough. For this, she could initially spend her resources in perks rather than in acquiring skills or material to maintain the asset to a good second-hand value. Cost padding with no "shadow cost", where the manager can appropriate every unit of an increase in $K$, is also similar to investing in the alternative project. The monopolist could increase $K$ and spend the additional cost in perks. 
Corollary 1 : Cost padding up to $K=w+L_{1}$ is optimal and leads to a unique separating equilibrium with $p_{1}=V_{h}(1+\delta)$.

The results above are very clear-cut because they assume that the monopolist can fully use the resources she diverts. It may be the case, though, that she can only partly benefit from the resources she diverts. Our results are reasonably robust to this assumption. As a benchmark case, we turn to a monopolist who cannot enjoy anything from the diverted resources.

Proposition 2 : Assume that the monopolist cannot use the resources she diverts. Then, there exist $\lambda_{a}$ and $\lambda_{b}$, with $\lambda_{b}>\lambda_{a}$ for some parameter values, such that when $\lambda_{1} \in\left[\lambda_{a}, \lambda_{b}\right]$, the monopolist initially burns $w-\left(K-L_{1}\right)$, borrows $B=L_{1}$ (debt capacity) and charges a fully separating price $p_{1}=$ $V_{h}(1+\delta)$

\section{Proof: See Appendix.}

The strategic use of debt in promoting information revelation arises from the feature that no sale triggers complete liquidation. This occurs if no money is left to renegotiate at the end of stage 1 . When the only possibility is to burn the money taken away from the project, restoring the static monopoly power entails an additional cost. The range of $\lambda_{1}$ such that the equilibrium is separating is reduced by the monopolist's inability to benefit from money diversion.

When $\lambda_{1}$ is large (when the incentive to discriminate is high), the utility in the separating equilibrium decreases with $w_{p}$. She is willing to burn money as it allows her to restore her monopoly power. Nonetheless, she only does so if her utility after burning money is higher than what she would obtain in another equilibrium. This condition is met when $\lambda_{1}$ is not too large. By burning money, the monopolist can endogeneize $f$ because it reduces her initial wealth ${ }^{11}$.

\footnotetext{
${ }^{11}$ If the monopolist can divert resources to her own benefit ex ante, $L_{2}>0$ does not affect Proposition 1. If she cannot, the results of Proposition 2 still hold with $\lambda_{a}^{\prime} \leq \lambda_{a}$ and $\lambda_{b}^{\prime}<\lambda_{b}$
} 
If money burning is impossible and $\lambda_{1} \in\left[\lambda_{a}, \lambda_{b}\right]$, then a high cost to undertake the project and/or a low initial wealth (respectively up and down to $\left.K=w+L_{1}\right)$ are utility increasing. The higher $K$ and the lower $w$, the greater the scope for liquidation if the buyer of type $h$ does not buy in stage 1 and the higher his willingness to buy in stage 1. A high cost reduces the profitability of the project, but increases the monopolist's expected payoff.

\subsubsection{Financial Constraints and Production to Order versus Pro- duction to Market}

Our previous results are driven by the assumption that liquidation restricts production. It would not be the case if the monopolist produced to market (before the buyer decision is made). If so, debt would not constrain her capacity to supply the good: even if the firm was totally liquidated, the good would still be available to the buyer and the threat of liquidation would not affect the buyer's decision (unless the monopolist owns the delivery technology). Thus, we have:

Corollary 2 : Retaining the assumptions of Proposition 1 or 2 under which the equilibrium in the product market is separating, under production to order, the monopolist's utility and debt are higher than under production to market.

However, in the semi-separating equilibrium, liquidation does not affect the buyer's probability of ordering the good in stage 1 . Producing to market in stage 1 allows the monopolist to produce one unit before being at least partly liquidated. This increases her stage 2 expected profit. Thus, in the semiseparating equilibrium, production to market dominates production to order.

\subsubsection{Debt and the Durability of the Good}

Assume that, with probability $\alpha$, a buyer ordering the good at stage 1 can still consume it at stage 2 . With probability $1-\alpha$, he cannot consume it any decreasing with $L_{2}$ (indeed, the fraction liquidated would be $f^{\prime}=\frac{L_{1}-\left(K-w_{p}\right)}{L_{1}-\delta L_{2}}$ for $L_{2}$ not too high). 
more. In this case, he can buy another good at stage 2, given his first period decision gave information to the monopolist about his type. We refer to $\alpha$ as the durability of the good. Whether the good is durable or not is revealed at the beginning of stage 2 .

Clearly, the final stage strategies in the product market are as in the durable good case. $f$ is also determined as before. Proceeding as in section 2.2, we obtain:

$$
\begin{aligned}
\hat{p}_{1} & =V_{h}(1+\alpha \delta)-\delta f\left(V_{h}-V_{l}\right) \\
U_{s}-U_{s s} & =\frac{1-\lambda_{1}}{1-\bar{\lambda}}\left[V_{l}(1-\delta+\alpha \delta)+\bar{\lambda} \max \left\{L_{1},(1-\alpha) \delta V_{h}\right\}\right] \\
& +\left(1-\lambda_{1}\right) L_{1}+\frac{1-\lambda_{1}}{1-\bar{\lambda}}(K-w)\left(\delta V_{l} / L_{1}-1\right)
\end{aligned}
$$

$U_{s}-U_{s s}$ is still positive and increases with $\alpha$. We thus obtain:

Proposition 3 : There is a unique fully separating equilibrium with $w_{p, s}=$ $K-L_{1}$ and maximum indebtness. The increase in the monopolist's utility due to this strategic use of debt increases with the durability of the good.

In other words, the benefit from being financially constrained increases with the durability of the good. This is natural since the less durable the good, the less competition the monopolist faces with herself over time. The special case $\alpha=0$ refers either to the sale of a non durable good or to the rental of a durable good. In this case, the supplier faces the well-known ratchet effect which is developed in a richer setting in Section $3^{12}$.

\footnotetext{
${ }^{12}$ In a richer setup, the higher benefit from using debt associated with a more durable good may have to be balanced with a lower debt capacity. If the creditor had some bargaining power, the debt capacity (and, for a given $w_{p}, 1-f$ ) would decrease with the durability of the good. Indeed, when the good is more durable, the expected profit at stage 2 is higher and the monopolist is ready to pay more to keep a high fraction of the asset. Hence, a more durable good implies a higher incentive to be financially constrained but a lower debt capacity.
} 


\section{Ratchet Effect with Menu Offers and Debt}

The durable good case makes the monopolist's competition with herself over time extreme. When the good is not durable, the monopolist's profit is still constrained by the ratchet effect. The intuition behind this effect is that a high valuation buyer may refuse to buy the good at a high price as this would reveal information which would induce the monopolist to charge a high price in next stages. The ability to discriminate between types is limited because the high valuation buyer compares his future rent when he mimicks the low valuation one today and when he does not. The positive rent differential makes information revelation more difficult than in the static case (although the problem is not as severe as in Coasian dynamics).

In this section, it is shown that the positive effect of debt on information revelation pertains even though (1) the demand curve is more general and the monopolist may use non linear pricing rules (second degree price discrimination) and (2) the buyer is not pivotal. So far, the incentives for a high valuation buyer to buy early were maximized: no sale at $t=1$ triggered complete liquidation of the monopolist. Here, instead of focusing on renegotiation issues between the monopolist and the creditor, we assume that the former can be liquidated independently of the buyer's decision. Since debt comes together with a possibility of liquidation, it still decreases the expected rent of mimicking a lower type buyer. However, the benefit from debt is smaller than in the durable good case ${ }^{13}$.

\subsection{The Product Market}

We extend the previous model to the case where the quantity is variable and where the monopolist can make menu offers stipulating a quantity and a tariff. We adapt Laffont and Tirole's $(1988,1993)$ approach to this dynamic version

\footnotetext{
${ }^{13}$ When the good is not durable and buyers are anonymous, there is no dynamic adverse selection. The monopolist does not compete with herself over time and debt loses its strategic value.
} 
of Maskin and Riley's (1984) model ${ }^{14}$.

The good is perishable, i.e. it can be consumed for one stage only. Alternatively, one may consider that the buyer can only rent the durable good. It is assumed that the buyer is not anonymous: in stage 2, the monopolist remembers the first stage offer and the buyer's previous decision. Following Laffont and Tirole (1988), we assume that a buyer who bought at $t=1$ can refuse to consume at $t=2$ (these authors refer to this strategy as a "take the money and run" strategy). At each stage, the buyer's utility is:

$$
U_{t}^{i}=\theta_{i} V\left(q_{t}\right)-T_{t}, \quad t=1,2
$$

with $\theta_{i} \in\left\{\theta_{l}, \theta_{h}\right\}$ and $V^{\prime}>0, V^{\prime \prime}<0$. Denote the probability $\operatorname{Prob}\left(\theta=\theta_{h}\right)=$ $\lambda_{1}$. At each date, the monopolist offers a contract $\left\{q_{t}, T_{t}\right\}$. Therefore, the product market of the previous section is a special case with $q_{t} \in\{0,1\}$ and $V_{i}=\theta_{i} V(1)$.

For the sake of exposition, we recall the usual results in the static case. If $\theta_{i}$ is perfectly observable by the monopolist, the optimal contract maximizes $T_{i}-c q_{i}$, where $c$ is the marginal cost, subject to $\theta_{i} V\left(q_{i}\right)-T_{i} \geq 0$. For each type, the monopolist offers the first best quantity (such that $\theta_{i} V^{\prime}\left(q_{i}^{f b}\right)=c$ ) and the buyer receives zero rent. Now, if $\theta_{i}$ is private information to the buyer, the monopolist discriminates the two types by offering quantities (see Maskin and Riley, 1984):

$$
\begin{aligned}
\theta_{h} V^{\prime}\left(q_{h}^{f b}\right) & =c \\
\theta_{l} V^{\prime}\left(q_{l}^{s b}\right) & =c+\frac{\lambda_{1}}{1-\lambda_{1}} \Delta \theta \cdot V^{\prime}\left(q_{l}^{s b}\right)
\end{aligned}
$$

\footnotetext{
${ }^{14}$ Laffont and Tirole show that screening amongst agents is impossible when the private information parameter is a continuous variable. This negative result comes from an "extreme" version of the ratchet effect in the sense that privately informed agents are allowed to quit the relationship in the second stage. The non screening result still holds in our model with a continuum of types. Nonetheless, we show that debt increases the scope for screening and reduces the ratchet effect.
} 
where $\Delta \theta=\theta_{h}-\theta_{l}$. A low valuation buyer has no rent, $T_{l}=\theta_{l} V\left(q_{l}^{s b}\right)$. As $T_{h}=\theta_{h} V\left(q_{h}^{f b}\right)-\Delta \theta V\left(q_{l}^{s b}\right)$, the rent of a high valuation buyer is equal to $\Delta \theta V\left(q_{l}^{s b}\right)$. Let $\pi^{A I}$ be the monopolist's profit under asymmetric information, we have ${ }^{15}$ :

$$
\pi^{A I}=\lambda_{1}\left(\theta_{h} V\left(q_{h}^{f b}\right)-c q_{h}^{f b}\right)-\lambda_{1} \Delta \theta V\left(q_{l}^{s b}\right)+\left(1-\lambda_{1}\right)\left(\theta_{l} V\left(q_{l}^{s b}\right)-c q_{l}^{s b}\right)
$$

\subsection{The Two-Stage Case with Debt}

We assume that when the firm is indebted, there is an exogenous probability of liquidation, $1-f$. Once more, the analysis in the preceding section may justify why this probability is non null even though liquidation is inefficient.

When the monopolist cannot commit to a particular future contract, the stage 2 contract is the optimal one (ex post) given her beliefs. Let $\lambda_{2}^{k}$ be her belief that the buyer is of type $h$ after the contract $k$ was chosen at stage 1 . If $\lambda_{2}^{k}<1$, then the stage 2 offer is the second best static one with beliefs $\lambda_{2}^{k}$ and the profit is $\pi^{A I}\left(\lambda_{2}^{k}\right)$ this holds when $\lambda_{2}^{k}=0$ as well). If $\lambda_{2}^{k}=1, M$ knows that the buyer has a high valuation and offers the first best quantity at a price $\theta_{h} V\left(q_{h}^{f b}\right)$. Consequently, the high valuation buyer's rent is null $\left(U_{2}^{h}=0\right)$.

We now turn to stage 1 . Assume, for the sake of the argument, that the usual second-best contract is offered in stage 1. A type $h$ buyer's incentive constraint is binding, meaning that in stage 1 he is indifferent between choosing $\left\{q_{h}^{f b}, T_{h}^{f b}\right\}$ and $\left\{q_{l}^{s b}, T_{l}^{s b}\right\}$. If he picks $\left\{q_{h}^{f b}, T_{h}^{f b}\right\}$, he is identified as a type $h$ buyer, which implies that $U_{2}^{h}=0$ and that his intertemporal utility equals his first stage utility $\Delta \theta V\left(q_{l}^{s b}\right)$. If he chooses $\left\{q_{l}^{s b}, T_{l}^{s b}\right\}$, he still gets a stage 1 utility $\Delta \theta V\left(q_{l}^{s b}\right)$, but since he is not identified as a type $h$ buyer, he has a positive rent in stage $2\left(\delta U_{2}^{h}>0\right)$. Hence, his intertemporal utility is higher, i.e. the usual second-best contract is no longer incentive compatible. The following figure illustrates the intuition:

\footnotetext{
${ }^{15}$ In this static case, we assume that no shutdown occurs: it is optimal to sell to the type $l$ buyer because neither $\lambda_{1}$ nor $\Delta \theta$ is very high.
} 


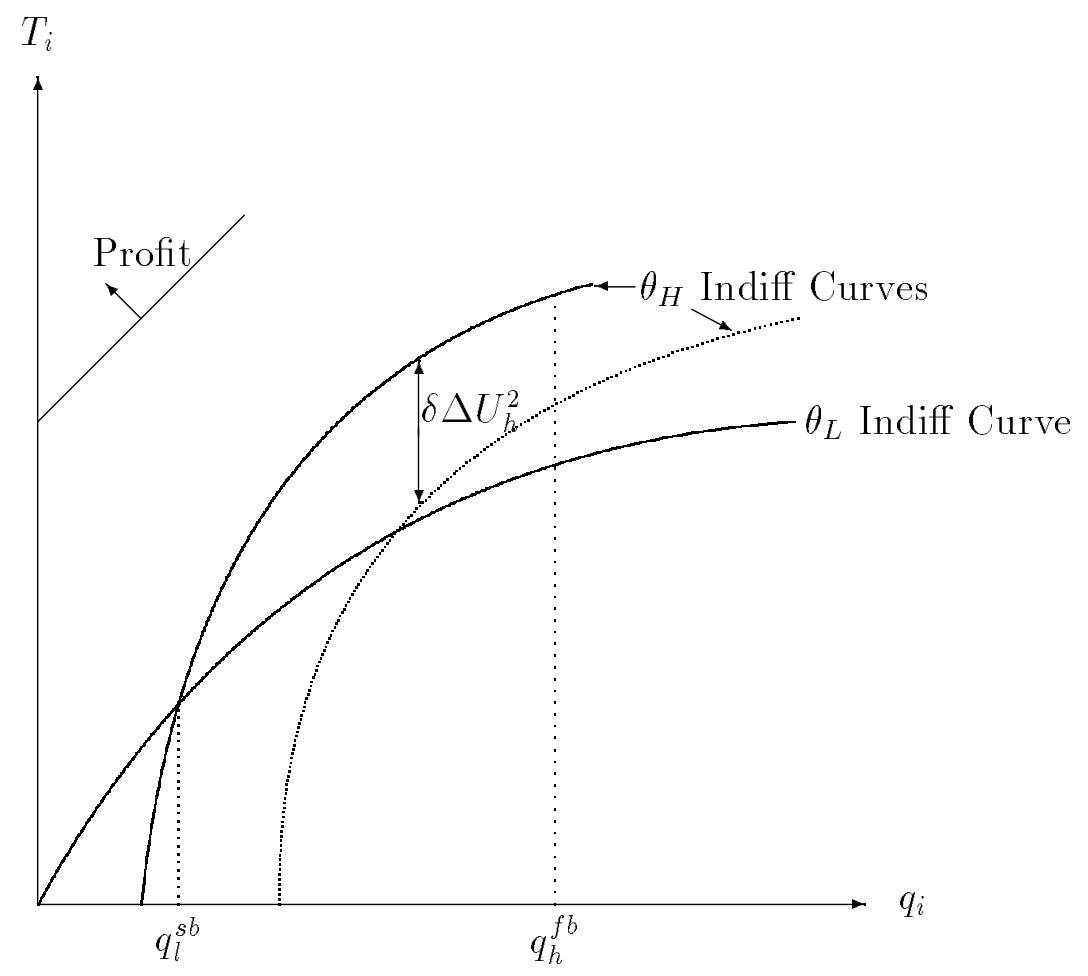

The two points on the bold $\theta_{h}$-indifference curve represent the static solution. For the high valuation buyer to consume the first best quantity at $t=1$, the monopolist must lower the first stage payment by $\delta \Delta U_{2}^{h} . \Delta U_{2}^{h}$ represents the differential at $t=2$ for a high valuation buyer between utility deriving from his choices at $t=1\left(\left\{T_{l}, q_{l}\right\}\right.$ or $\left.\left\{T_{h}, q_{h}\right\}\right)$. The high valuation buyer's rent in stage 2 is greater when the monopolist believes that the type is low. The third point is incentive compatible. Yet, for a high second stage "extra" rent, a high valuation buyer reveals his type only for a large decrease in $T_{1}^{h}$. For this reason, a low valuation buyer may prefer to choose the allocation proposed for the high valuation buyer. This is possible if the low type erroneously identified as a high type can quit the market at $t=2$ : at this date, the monopolist, believing that the buyer's type is $\theta_{h}$, makes an offer that is binding out the high valuation buyer's individual rationality constraint. If the low type is forced to accept this contract, his utility is negative and incentive compatibility at $t=1$ is restored. Under the alternative assumption, screening the different types may 
not be possible. In particular, if $\theta_{h}-\theta_{l}$ is small (in the continuous case), the translated $\theta_{h}$-indifference curve crosses $q=q^{f b}$ below the $\theta_{l}$-indifference curve. Even in a 2 type case, different classes of equilibria may arise (according to which incentive constraint binds) and a pooling contract may be optimal.

In this setting, debt alleviates the dynamic adverse selection problem. A type $h$ buyer will enjoy an "extra" rent at $t=2$ with probability $f$ only: the benefit of misreporting his type is lower since the buyer's utility at $t=2$ will be null with probability $1-f^{16}$. Graphically, the $\theta_{h}$-indifference curve is translated by $\left.f \delta \Delta U_{2}^{h}\right)$.

Proposition 4 There exists $\delta_{0}(f)$ such that the equilibrium is separating for any $\delta \leq \delta_{0}(f)$ and pooling otherwise. $\delta_{0}(\cdot)$ increases with the probability of liquidation.

\section{Proof: Appendix.}

An increase in the probability of liquidation favours separating equilibria. The fact that the monopolist may not supply the market in the future decreases the benefit of mimicking a low valuation buyer. The strategic use of debt reduces the informational rent given up to the buyer. The cost of debt is that the monopolist may lose the second stage profit. When the discount factor is low, she puts more weight on the present gain than on future losses. The threshold increases with the probability of liquidation as more liquidation increases both the first stage gain and the second stage loss.

Interestingly, this effect of debt on the revelation of information would persist if the buyer instead of the monopolist may be liquidated. In this case, debt only advantages the monopolist, provided a bankrupt buyer is replaced by a new one at $t=2$ (otherwise, debt entails a cost identical to the previous one). An indebted buyer, who decides at $t=1$ to misreport his type, expects

\footnotetext{
${ }^{16}$ The existence of a new entrant in stage 2 would not affect our result as long as the monopolist's information is not transferable.
} 
an extra gain at $t=2$ with probability $f$. This observation is particularly relevant in the original Laffont-Tirole setting where the "buyer" is a regulated firm. If this firm is indebted, the regulator may obtain information about its cost more easily. Debt forces the firm to adopt short term objectives. As a result, problems of dynamic adverse selection are less severe. In a regulation framework, our conclusion would be that debt is welfare increasing and that the regulator would benefit from its use. This result has to be contrasted with Spiegel and Spulber's (1995) paper where a regulated firm uses debt as a way of extorting rents from the regulator: to avoid bankruptcy, the regulator increases the price that the regulated firm is allowed to charge. The total effect of debt depends on whether the regulator can commit to let the regulated firm go bankrupt or not.

The previous result may also illustrate the relationship between a worker who is privately informed about his productivity and an employer. In a two period model, the firm would offer a contract stipulating an output and a wage at each date and the worker would have to decide whether or not he accepts to reveal his productivity. The objective, and the constraints as well, of the employer are identical to those of the monopolist; the worker's decision is of the same nature as the buyer's one. Note that, in this type of problem, the assumption that the worker is non pivotal is generally fairly justified. Now, if the employer cannot commit to a wage and a performance requirement for the two periods, any information revealed in the first stage will be used strategically. A highly productive worker, anticipating employer's opportunism is reluctant to reveal his type. Such a behavior, at every level of an organization, leads to suboptimal performances. With the same reasoning, it appears that debt may help to solve this dynamic problem. Hence, debt may also promote internal efficiency. This interpretation is consistent with the SAC example. Wruck emphasizes that the existence of debt has changed internal behaviors. She also shows that prior attempts, without the existence of debt, had failed 
to achieve this goal. We attribute this cultural change to the existence of a credible possibility, associated with debt, that long-term relationships may be broken. Individuals are then more willing to reveal their information.

\section{Concluding Remarks}

Focusing on the example of a monopolist engaged in a repeated relationship with a privately informed buyer, this paper has shown that debt can be thought of as a mechanism to elicit information. A strategic use of debt can solve dynamic adverse selection problems and can benefit the uninformed party. Our results prove to be quite robust to different extensions of the dynamic problem considered as well as to alternative financial contracts or product market situations. This argument can be viewed as complementary to moral hazard ones like the free cash flow theory to help understand the way "hard claims" like debt can promote efficiency in organizations.

Our paper is also to be contrasted with signalling theories of financing decisions (see, for instance, Ross (1977), Myers and Majluf (1984)). These theories typically analyze the financing decisions of a privately informed manager facing uninformed investors. In this paper, there is no such asymmetric information. The financing decision is made by an uninformed party engaged in a long-term relationship with another privately informed party. We are not aware of any other theory of debt considering this type of situations. 


\section{APPENDIX:}

\section{Proof of Proposition 1:}

The monopolist allocates $w$ between $w_{p}$ and $w_{0}$. The way she allocates money among the two projects enables her to manipulate the fraction of the asset she can keep if the buyer does not buy the good in stage 1 .

$$
\begin{aligned}
U_{s} & =\delta f_{s} V_{l}+\lambda_{1}\left[V_{h}\left(1+\delta\left(1-f_{s}\right)\right)+L_{1}-\left(K-w_{p, s}\right)\right]+w-w_{p, s} \\
U_{s s} & =\frac{\lambda_{1}-\bar{\lambda}}{1-\bar{\lambda}}\left[V_{h}(1+\delta)-\left(K-w_{p, s s}\right)+L_{1}\right] \\
& +\frac{1-\lambda_{1}}{1-\bar{\lambda}} \delta f_{s s} V_{l}+w-w_{p, s s}
\end{aligned}
$$

$U_{s}$ decreases with $f_{s}$ and $U_{s s}$ increases with $f_{s s}$. The monopolist chooses between a separating equilibrium with $f_{s}=0$ (investing $L_{1}-\left(K-w_{p, s}\right)$ in the alternative project) and a semi-separating equilibrium with a $f_{s s}$ as high as possible (where $w_{p, s}=w$, i.e. all the money is invested in entering the durable good market). The separating payoff dominates the semi-separating one if and only if:

$$
\begin{aligned}
\lambda_{1} V_{h}(1+\delta)+w-\left(K-L_{1}\right) & >\frac{\lambda_{1}-\bar{\lambda}}{1-\bar{\lambda}}\left[V_{h}(1+\delta)+L_{1}-(K-w)\right] \\
& +\frac{1-\lambda_{1}}{1-\bar{\lambda}}\left[L_{1}-(K-w)\right] \delta V_{l} / L_{1}
\end{aligned}
$$

which is always satisfied. In addition, it is easy to check that the pooling equilibrium is always dominated by the separating one with $f_{s}=0$.

\section{Proof of Proposition 2:}

Assume now that the monopolist cannot appropriate any resources she diverts from the project. She cannot manipulate $f$ (which is fully determined by $L_{1}$ 
and $K-w_{p}$ ) without completely wasting the resources she diverts. In this case, there is a tradeoff between having more money initially and making more profit by being financially constrained. The separating outcome with money burning requires that:

- The separating utility decreases with $w_{p}$. This holds if and only if $\lambda_{1}>$ $\delta V_{l} /\left[\left(\delta V_{h}-L_{1}\right)\right.$. In this case, $U_{s}$ is maximised when $w-\left(K-L_{1}\right)$ is burnt, which implies $f=0$ and leads to $U_{s}=\lambda_{1} V_{h}(1+\delta)$.

- This outcome is preferred to both the semi-separating one and the pooling one (when no money is burnt since the monopolist's utility increases with $w$ in both cases). This holds if and only if:

$$
\begin{aligned}
& \lambda_{1} \leq \lambda_{b} \equiv \frac{V_{l}(1+\delta)-\left(\delta V_{l} / L_{1}-V_{l} / V_{h}\right)\left(L_{1}-(K-w)\right)}{V_{l}(1+\delta)-\left(\delta V_{l} / L_{1}-1\right)\left(L_{1}-(K-w)\right)} \\
& \lambda_{1} \geq V_{l} / V_{h}+\left(L_{1}-(K-w)\right) / V_{h}(1+\delta)
\end{aligned}
$$

$\lambda_{b}$ increases with $K$, decreases with $w$ and equals 1 when $L_{1}=K-w$.

The result is obtained with $\lambda_{a} \equiv \max \left\{\delta V_{l} /\left[\left(\delta V_{h}-L_{1}\right)\right], V_{l} / V_{h}+\left(L_{1}-(K-\right.\right.$ $\left.w)) / V_{h}(1+\delta)\right\}$

\section{Proof of Proposition 4:}

Following Laffont and Tirole, we assume that the monopolist offers two contracts in stage $1:\left\{q^{0}, T^{0}\right\}$ for the low valuation buyer and $\left\{q^{1}, T^{1}\right\}$ for the high valuation one. Let $x$ be the probability that a high valuation buyer chooses $\left\{q^{0}, T^{0}\right\}$ and $y$ be the probability that a low valuation buyer chooses $\left\{q^{0}, T^{0}\right\}$. The updated probability that $\theta=\theta_{h}$ given that $\left\{q^{k}, T^{k}\right\}$ was chosen in stage $1, \lambda_{2}^{k}$, satisfies: 


$$
\begin{aligned}
\lambda_{2}^{1} & =\frac{\lambda_{1}(1-x)}{\lambda_{1}(1-x)+\left(1-\lambda_{1}\right)(1-y)} \\
\lambda_{2}^{0} & =\frac{\lambda_{1} x}{x \lambda_{1}+y\left(1-\lambda_{1}\right)}
\end{aligned}
$$

We solve the game by backward induction. In stage 2, the monopolist's program, offers and profit are those of the static case given $\lambda_{2}^{k}$. In stage 1 , the monopolist's program can be written:

$$
\begin{array}{ll}
\max _{\left\{q^{0}, T^{0}, q^{1}, T^{1}\right\}} & \lambda_{1}\left[x\left(T^{0}-c q^{0}\right)+(1-x)\left(T^{1}-c q^{1}\right)\right] \\
& +\left(1-\lambda_{1}\right)\left[y\left(T^{0}-c q^{0}\right)+(1-y)\left(T^{1}-c q^{1}\right)\right] \\
& +\delta f\left[\left(\lambda_{1} x+\left(1-\lambda_{1}\right) y\right) \pi^{A I}\left(\lambda_{2}^{0}\right)\right. \\
& \left.+\left(\lambda_{1}(1-x)+\left(1-\lambda_{1}\right)(1-y)\right) \pi^{A I}\left(\lambda_{2}^{1}\right)\right] \\
\text { s.t. } \quad & \theta_{h} V\left(q^{1}\right)-T^{1}+\delta f U_{2}^{h}\left(\lambda_{2}^{1}\right) \geq \theta_{h} V\left(q^{0}\right)-T^{0}+\delta f U_{2}^{h}\left(\lambda_{2}^{0}\right) \\
\left(I C_{h}\right) \quad & \theta_{l} V\left(q^{0}\right)-T^{0} \geq \theta_{l} V\left(q^{1}\right)-T^{1} \\
\left(I C_{l}\right) \quad & \theta_{h} V\left(q^{1}\right)-T^{1}+\delta f U_{2}^{h}\left(\lambda_{2}^{1}\right) \geq 0 \\
\left(I R_{h}\right) \quad & \theta_{l} V\left(q^{0}\right)-T^{0} \geq 0
\end{array}
$$

It is clear that $\left(I R_{l}\right)$ is binding. In the Laffont-Tirole setting, 3 cases may arise: either only $\left(I C_{h}\right)$ is binding, or only $\left(I C_{l}\right)$ is binding or both bind. It turns out that in our case either only $\left(I C_{h}\right)$ is binding or the solution is pooling. This difference arises because, in the Laffont-Tirole monopolist case, the isoprofit curves are strictly convex. So we have two types of equilibria.

In type I equilibrium, $\left(I C_{h}\right)$ only is binding, so that the low valuation buyer strictly prefers $\left\{q^{0}, T^{0}\right\}$ and the high valuation buyer randomizes between $\left\{q^{0}, T^{0}\right\}$ and $\left\{q^{1}, T^{1}\right\}$. As a result, $\lambda_{2}^{1}=1$ and $\lambda_{2}^{0}=x \lambda_{1} /\left[x \lambda_{1}+1-\lambda_{1}\right]$. Therefore, $U_{2}^{h}\left(\lambda_{2}^{1}\right)=0$ and the second period payoff to the monopolist is first best. With probability $\lambda_{1}(1-x), \pi_{2}=\pi^{A I}(1) \equiv \pi_{1}^{F I}$. With the complementary probability, $U_{2}^{h}\left(\lambda_{2}^{0}\right)=\Delta \theta V^{\prime}\left(q_{l}^{s b}\left(\lambda_{2}^{0}\right)\right)>0$. The expected payoff to the monopolist is: 


$$
\begin{aligned}
\Pi & =\lambda_{1}\left[x\left(\theta_{l} V\left(q_{l}^{s b}\right)-c q_{l}^{s b}\left(\lambda_{1}\right)\right)+(1-x)\left(\theta_{h} V\left(q_{h}^{f b}\right)-c q_{h}^{f b}\right)\right] \\
& -\lambda_{1}\left[\Delta \theta V\left(q_{l}^{s b}\left(\lambda_{1}\right)\right)+\delta f \Delta \theta V\left(q_{l}^{s b}\left(\lambda_{2}^{0}\right)\right)\right] \\
& \left.+\left(1-\lambda_{1}\right)\left[\theta_{l} V\left(q_{l}^{s b}\left(\lambda_{1}\right)\right)-c q_{l}^{s b}\right)\right] \\
& +\delta f\left[\left(\lambda_{1} x+\left(1-\lambda_{1}\right)\right) \pi^{A I}\left(\lambda_{2}^{0}\right)+\lambda_{1}(1-x) \pi_{1}^{F I}\right]
\end{aligned}
$$

Type II equilibrium is pooling. The best pooling equilibrium is such that $\theta_{l} V^{\prime}\left(q^{p}\right)=c$, i.e. $q^{p}=q_{l}^{f b}$ and gives the monopolist a payoff:

$$
\Pi^{p}=\pi_{1}^{p}+\delta f \pi^{A I}\left(\lambda_{1}\right)
$$

The best type I equilibrium is separating with $x=0$, yielding an expected payoff:

$$
\begin{aligned}
\Pi^{s} & =\lambda_{1}\left(\theta_{h} V\left(q_{h}^{f b}\right)-c q_{h}^{f b}\right)-\lambda_{1}\left[\Delta \theta V\left(q_{l}^{s b}\left(\lambda_{1}\right)\right)+\delta f \Delta \theta V\left(q_{l}^{s b}\left(\lambda_{2}^{0}\right)\right)\right] \\
& \left.+\left(1-\lambda_{1}\right)\left[\theta_{l} V\left(q_{l}^{s b}\left(\lambda_{1}\right)\right)-c q_{l}^{s b}\right)\right] \\
& +\delta f\left[\left(1-\lambda_{1}\right) \pi^{A I}\left(\lambda_{2}^{0}\right)+\lambda_{1} \pi_{1}^{F I}\right]
\end{aligned}
$$

In this case, since $\lambda_{2}^{0}=0$, we obtain, by denoting $\pi_{0}^{F I} \equiv \pi^{A I}(0)$ :

$$
\begin{aligned}
\Pi^{s} & =\pi^{A I}\left(\lambda_{1}\right)-\delta f \lambda_{1} \Delta \theta V\left(q_{l}^{f b}\right) \\
& +\delta f\left[\left(1-\lambda_{1}\right) \pi_{0}^{F I}+\lambda_{1} \pi_{1}^{F I}\right]
\end{aligned}
$$

By definition of $\pi^{A I}\left(\lambda_{1}\right)$, we have:

$$
\lambda_{1} \pi_{1}^{F I}+\left(1-\lambda_{1}\right) \pi_{0}^{F I}-\Delta \theta \lambda_{1} V\left(q_{l}^{f b}\right)<\pi^{A I}\left(\lambda_{1}\right)
$$

Otherwise, the optimal second best contract would not maximise the monopolist's payoff in the static case. Using the same argument, it is clear that $\pi^{A I}\left(\lambda_{1}\right)>\pi_{1}^{p}$. Hence, $\Pi^{p}<\Pi^{s}$ if and only if: 


$$
\pi_{1}^{p}-\pi^{A I}\left(\lambda_{1}\right)<\delta f\left[\left(1-\lambda_{1}\right) \pi_{0}^{F I}+\lambda_{1} \pi_{1}^{F I}-\Delta \theta V\left(q_{l}^{f b}\right)-\pi^{A I}\left(\lambda_{1}\right)\right]
$$

that is if and only if:

$$
\delta<\frac{\pi^{A I}\left(\lambda_{1}\right)-\pi_{1}^{p}}{f\left[\Delta \theta V\left(q_{l}^{f b}\right)+\pi^{A I}\left(\lambda_{1}\right)-\left(1-\lambda_{1}\right) \pi_{0}^{F I}-\lambda_{1} \pi_{1}^{F I}\right]}
$$

Denoting the right hand side by $\delta_{0}(f)$ gives the result. 


\section{REFERENCES}

Bolton, P. and D. Scharfstein (1990), “A Theory of Predation Based on Agency Problems in Financial Contracting", American Economic Review, 80, 93-106.

Bolton, P. and D. Scharfstein (1996), "Optimal Debt Structure with Multiple Creditors", Journal of Political Economy, 104. 1-25.

Coase R. (1972), "Durability and Monopoly", Journal of Law and Economics, $15,143-49$.

Dewatripont M. (1988), "Commitment through Renegotiation-Proof Contracts with Third Parties", Review of Economic Studies, 55, 377-90.

Freixas, X., R. Guesnerie and J. Tirole (1985), "Planning under Incomplete Information and the Ratchet Effect", Review of Economic Studies, 52, 173-91.

Fudenberg, D., D. Levine and J. Tirole (1987), "Incomplete Information Bargaining with Outside Opportunities", Quarterly Journal of Economics, $37-50$.

Grossman, S. and O. Hart (1982), "Corporate Financial Structure and Managerial Incentives", in The Economics of Information and Uncertainty, J.J. McCall (ed.), University of Chicago Press, 107-40.

Harris, M. and A. Raviv (1990), "Capital Structure and the Informational Role of Debt", Journal of Finance, 45, 321-49.

Harris and Raviv (1991), "The Theory of Capital Structure", Journal of Finance, 46, 297-355.

Hart O. (1993), "Theories of Optimal Capital Structure: The Managerial Discretion Perspective", in The Deal Decade: What Takeovers and Lever- 
aged Buyouts Mean for Corporate Governance, Margaret Blair (ed.), The Brookings Institutions, 19-53.

Hart O. (1995), Firms, Contracts and Financial Structure, Clarendon Lectures in Economics, Oxford Univesity Press.

Hart, O. and J. Moore (1989), "Default and Renegotiation: A Dynamic Model of Debt", MIT working paper no. 520 .

Hart, O. and J. Moore (1996), "Debt, Default and Renegotiation, mimeo Harvard University and LSE.

Hart, O. and J. Tirole (1988), "Contract Renegotiation and Coasian Dynamics", Review of Economic Studies, 55, 509-40.

Jensen M. (1986), “Agency Costs of Free Cash Flow, Corporate Finance, and Takeovers", American Economic Review, 76, 323-29.

Jensen M. (1988), "Takeovers: Their Causes and Consequences", Journal of Economic Perspectives, 2(1), 21-48.

Jensen, M. and W. Meckling (1976), "Theory of the Firm: Managerial Behavior, Agency Costs and Ownership Structure", Journal of Financial Economics, 3, 305-60.

Laffont, J. J. and J. Tirole (1988), "The Dyamics of Incentive Contracts", Econometrica, 56, 1153-75.

Laffont, J. J. and J. Tirole (1993), A Theory of Incentives in Procurement and Regulation, MIT Press.

Maskin, E., and J. Riley (1984), "Monopoly with Incomplete Information", Rand Journal of Economics, 15, 171-96.

Myers S. and Majluf (1984), "Corporate Financing and Investment Decisions when Firms have Information that Investors do not Have", Journal of 
Financial Economics, 13, 187-221.

Perotti, E. C. and K. E. Spier (1993), "Capital Structure as a Bargaining Tool: The Role of Leverage in Contract Renegotiation", American Economic Review, 83 (December).

Ross S. (1977), "The Determination of Financial Structure: the IncentiveSignalling Approach", Bell Journal of Economics, 8, 23-40

Spiegel, Y. and D. Spulber, "The Capital Structure of Regulated Firms", Rand Journal of Economics, 25, 424-50.

Tirole J. (1988), The Theory of Industrial Organization, MIT Press.

Titman S. (1984), “The Effect of Capital Structure on a Firm's Liquidation Decision", Journal of Financial Economics, 13, 137-51.

Wruck, K.R. (1994), "Financial policy, internal control, and performance: Sealed Air Corporation's leveraged special dividend", Journal of Financial Economics, 157-92.

Zwiebel J. (1992), “A Control Theory of Dynamic Capital Structure”, Stanford Graduate School of Business Research Paper No. 1235. 